\title{
Economic and Social Development Strategies and Models Specific for Romania Situation
}

\author{
Silviu-Marius Seitan ${ }^{1}$ \\ ${ }^{1}$ Financial and Monetary Researcg Center, Romanian Academy, Roman \\ Correspondence: Silviu-Marius Seitan, Ph.D., Financial and Monetary Researcg Center, Romanian Academy, \\ Roman. E-mail: seitansilviu@gmail.com
}

Received: May 20, 2021

doi:10.5430/ijba.v12n4p69
Accepted: June 1, 2021

Online Published: September 5, 2021

URL: https://doi.org/10.5430/ijba.v12n4p69

\begin{abstract}
The Paper begins with the presentation and analyze of some models and strategies for economic and social development meant to the Romanian needs and specific for the development of the rural area - as the main area in the country for the agriculture field development and also following some points and conditions used inside the European Union Member States. The named strategies and models was selected from a large group of strategies using, as the criteria, the Romanian needs and specific and also the European cooperation needs.
\end{abstract}

The second part of the paper presents the algorithm used for selecting model and strategy elements for creating a possible model for Romania situation.

Keywords: development, economic, social, stategis instruments

\section{JEL Classification: R 11}

\section{Literature Review}

The concept of community development has its origins (R. Phillips and R. Pittman (eds.), 2008) in the United States (USA) reform movements. During social movements in the United States, such as the Health Reform Movement of the 1840s or the Later Housing Reform, the term "collective action" appeared. Although the Progressive Movement of the 1890s meant much to community development, the social changes of the 1950s and 1960s (social movements for civil rights, anti-poverty) led to the recognition of community development (DC) as a practice. In the 1960s, thousands of community development corporations (CDCs) appeared in the United States.

The first definition of community development is attributed to the 1948 Cambridge Conference of Colonial Social Policy Administrators when it replaced the term mass education (Precupețu, pp. 6-8). In 1955, United Nations documents defined community development as a process aimed at creating the conditions for economic and social progress. Subsequently, the programs of international organizations facilitated the dissemination of the term in Africa and India.

The reactions to the top-down model of economic and social development adopted by UNICEF5 and WHO6 through the Alma Ata Declaration, led to the shaping of the current meaning of the term, namely the idea of involving people in their own development projects.

Two publications published in 1970, Community Development in the United Kingdom and Community Development: Journal of the Community Development Society in the USA (Phillips, Pittman, eds.) As well as the establishment of university programs in the field of community development, definitively imposed the concept of DC in areas such as public administration, urban planning or public order. Currently in the USA there are (idem) over 4000 CDCs, mostly focused on housing development, but also on areas related to business development, environment, labor, youth, etc.

Some attempts to define community development (ibidem) are focused on the process, ie on how people learn to work together to solve collective problems. Thus, Ploch defines community development as "a process of voluntary involvement of residents in a process of improving identifiable aspects of community life" which should normally lead to the strengthening, at Community level, of a model of relations. human and institutional (Ploch, pp5-15, apud ibidem p.6). 
On the other hand, there are definitions (Huie, 1976 in ibidem) based on outcome, ie the improvement of the place of life and work, through development programs and decision-making at the community level.

All these approaches to the concept have led to a comprehensive understanding (Phillips, Pittman eds.) Of community development, which is considered both a process (developing and strengthening the capacity to act collectively) and a result (collective adoption of measures and the result of joint action for community development).

The United Nations Children's Fund is based in New York and provides humanitarian and development assistance to children and their mothers in developing countries. It is an agency founded on a voluntary basis and operates from government funds and private donations.

The phrase community development has a relatively recent use in Romania, where it was taken from the programs of the European Union and the World Bank.

In the Romanian literature this concept is seen (Sandu, 2005, p. 15), as a "rediscovered social innovation", being considered a tolerant label for a family, relatively disorganized, of practices or models of local intervention that have or they tend to result in the best of the community (ibid., p. 23). " In a synthetic definition, in which DC "refers to voluntary changes in, through and for the community (idem, p. 15)" the voluntary involvement of community members in actions aimed at their own development is emphasized.

Definition: community development is the process by which a community improves its living conditions, through the voluntary, conscious and planned action of its members, based on the development of its own capacities for action, inter and extra-community connections, common values and use of internal resources; external.

Community development therefore covers all dimensions of development, economic, social, spatial and sustainable. To these can be added the cultural dimension, ie respect for cultural specificity, the assumption of identity based on traditional elements and the expression of cultural features, awareness of uniqueness in the wider cultural context.

\section{Theoretical Aspects}

\subsection{Marks}

Local economic development involves all municipality departments as well as other actors involved. Attention is recommended to ensure that economic development is organized very well. The first task is usually to review the city hall systems and procedures to encourage the growth of businesses and the location of businesses in the local Community.

\subsection{Models}

\subsubsection{The Need for Models}

The model in Community development is a concept that appears and develops with the crystallization of Community development initiatives in America and Canada and their transfer to Europe and other parts of the world.

The idea of model, as found in the theory of Community development, is quite broad, ranging from successful, more structured practices, model projects to structured theories applied to a field of development.

The need for models in Community development has arisen in the natural process of documenting (in the sense of establishing documents) and promoting practical development experience resulting from Community development programs.

The model is a structured form of Community action, which can be considered from a Community development perspective if it meets a minimum of criteria:

- aims to increase the community's share capital;

- aims to solve a problem (of a need) of people or of the whole Communities;

- involve people in action.

A Community development model will be mainly centered on one of the factors of social action at Community level which are only factors of social capital at local level and will provide a structured approach to Community-level intervention.

The main drivers of social action are:

- the initiator of the community development process - any development process; 
- the community has an initiator which may be internal or external, may be a community development program financier selecting a specific community or local actor (local institution, organization or leader) initiating a development process;

- agents of change - any community development process is selectively targeted only toward a local factor/actor that is transformed into an agent of change; diffuse multi-factor intervention can dilute the process and results at community level and involve additional resources;

- community / community involvement is one of the most important aspects of any community development process; without them the initiator of the community development process - any development process; two aspects are to be taken into account when it comes to community involvement in the community development process, and these two aspects are:

- degree of community involvement - information, consultation, participation and involvement of members of the community and

- ownership of the shares and the results of those actions; the community process is not enough to talk about involvement; the community, in order to achieve this, we need to plan a structured process with the community a process that can take many aspects - it can start from the community approach as a whole or from the different groups' approach.

\subsubsection{Theoretical Models}

In the following, it is considered necessary to present theoretical models of local development as these models can be considered as the standard models from which the development models used in practice were built.

However, it should also be noted that the theory of local development is still in the completion phase, as this chapter of the contemporary economy is still very new and will most likely be developed in parallel with practice.

Thus, it is considered important to present these theoretical models both as a basis for the current practical models and as a basis for the development and completion of this theory.

\subsubsection{The RuralNet Model - A Standard for Community Development}

The model developed by the RuralNet network can be considered a standard model in Community development not because it would be qualitative over the other models presented or would be a standard of what Community development in Romania is at present. This model is:

- a result of the analysis and composition of specific specific specific models and overlaps most appropriately with the idea that: Community development has at its heart the concept of social capital, a concept which is also the final outcome of any Community development approach;

- a theoretical model on which the analysis of practical models is based;

- a model with flexibility and ability to restructure according to reality and real evolution

Some of the features of the RuralNet model (which is also the basis of local development models used in Romania) characteristics demonstrated by arguments and complexity elements of the model that correspond to the requirements for implementing such a development model.

Firstly, the RuralNet model is centered on the Community development process and presents it with all the stages through which a community that is carrying out a planned development process should pass.

The steps in this process are:

I. Assessment of Community responsiveness

II. Identification of the network of relations in the community

III) The realization of the community profile

IV Community planning

V. Community action

VI Strategic planning

VII. Implementation of the strategic plan

VIII Assessment:

In the case of the aid, the aid is granted by the the development of the community's noise. 
The Community does not go through such a process alone; it is facilitated by a facilitator, which may be internal or external, facilitator using specific tools to generate change at community level, change taking place on a main stage of change in the level of social capital, first and foremost, the other changes relating to the development of the community become components of a secondary stage of change in that they are the results of changes, of the increase in the community's social capital.

Secondly, the RuralNet model is centered on the values and principles of Community development and for these reasons it is considered a model at a general level, one to structure the community development process and it can be found across all

The models applied in the social reality of Community development in Romania; but it is also a model to which all other models can be considered from the perspective of:

- the following are the logical steps of the community development process;

- the focus on social capital growth and not on the background of results;

- development at rural community level.

Thirdly, as a process by which the RuralNet model also moved into its development stages, it is the result of the application of the following models themselves and is also the result of the work of the practitioners who have implemented them together

These models within organizations active in Community development in Romania, Organizations that are members of or partner in the RuralNet network (e.g.: The Romanian Community Development Fund) and the researchers from the universities with which we carried out joint projects (West University of Timisoara, Babes Bolyai University of Cluj).

\section{The Community organization}

It is a model established in America, but rather recently entered Europe as the form of application at community level (mainly urban - but also applies to large rural communities or rural regions). His historian in Romania is linked to the Friederich Foundation Ebert Stiftung and to American Community organizer Paul Cromwel, who initiated in 2006 a training program in which they invited representatives of some institutions (cultural House) and NGOs from Romania.

The Community organization is rather a process based on the concept of "advocacy" as a form of community involvement in solving problems. However, it has an addition to the concept of "advocacy", plus it can be found in the idea of partnership with responsible public institutions in identifying solutions to the needs of citizens and the community.

The model is based on the basic idea that in the social area.

Three broad categories of actors are active in a Community: Public institutions (different forms of government). Economic organizations (businesses and other economic structures) and civil society (citizens and their various structures). The first two categories of structures are very well organized and often work together for their own interests, while civil society is usually poorly organized and does not have enough power to impose its own decisions. The Community organization aims to create and institutionalize an organization system that brings civil society to the level of partnership $\mathrm{n}$ decisions with the other two structures.

The basic principles governing the Community organization are:

- the compensation for the costs of the public service is not covered by the compensation, but by the compensation for the costs incurred by the public service providers

- powers to resolve community problems;

- the organization of the event is strong.

The main actions carried out in a Community organization process are those:

- influence on the authorities in order to carry out their tasks on the one hand, and on the other hand, citizens have demonstrated their power in relation to the authorities by influencing their decisions and leading to the resolution of Community needs/problems;

- Community organization puts people together balancing the balance of the citizen power - public authority. 
The agents of change involved in the Community organization process shall be:

- the community organizer

- the local volunteer team

- the team of leaders - people affected by need / problem

- citizens who support the need / problem solving

Community organization is a model that focuses on the organization process of people on the way they can put in value the power mainly due to their number and their ability to organize.

The steps the model assumes:

- training the volunteer team - it is the responsibility of the Community organizer He conducts unstructured interviews with local leaders, specialists, people recognized by the community. Among them will identify/select volunteer team members;

- leadership team training - is rather an action related to the financing of the Community organization process; it identifies those actors who can mobilize the necessary funds for the Community organization process;

"Listening" process - consists of conducting unstructured one-to-one interviews and is the most important tool in Community organization (except for the Community assembly), as well as being a "public" and "private" interview. Volunteers conduct unstructured interviews for 4 to 7 weeks with members of the community with the objective of:

- building confidence in the community's ability to solve its own problems;

- assessment of the motivational structure of the interviewees - to identify what

this would lead them to participate in the community assembly, how each person could be mobilized;

- identify the needs of the community - the needs that people feel, in order to

build the list of community needs/problems to be addressed;

- identification of affected persons and supporters. At this stage of interviews

- to identify who will attend the community meeting for each

- it also needs some people who have the ability to communicate how in

which a need/problem affects them personally.

Each volunteer will "listen" - conduct unstructured interviews with 10 to 12 members of the community (1 or 2 per week). The interview will take place at home at the Member of the community or at his/her office (if interviewed as public/specialist).

The prioritization of needs and the selection of needs to be addressed - is an activity by the volunteer group that is nothing more than a local team of facilitators. They expose the results of the interviews conducted and using specific techniques of prioritization and selection decide which Community problem they will address for the beginning and what order is proposed for to raise other community matters in the process of community organization.

Research - the technical study on the need to be addressed - Community development is not just an "advocacy" what adds to is the viable solution to solving the identified problem. Research into the problem is a study of the problem focusing on identifying different solutions and selecting the more efficient solution. This step is one that involves in addition to volunteers already present at the action level and the specialists/technicians needed to plan the solution. The research also includes the public authority responsible - the solutions proposed by it have been taken into account, and other solutions have been tested to find out the public authority's point of view of these solutions. It is also very important to consult citizens or even involve them in identifying the solution - in order to gain their support to the responsible public Authority.

Public meeting - is the most important stage of the Community Organization process. This stage demonstrates the "power" of organized people. The structure of the meeting and compliance with the program and its rules are very important elements for an effective Community organization process. The public meeting shall include the following essential elements in its conduct: 
In the case of a public meeting, the parties shall be represented by the members of the board of the board of the public meeting person in the community.

THE PUBLIC of the public - organized, strictly respecting the rules agreed with the volunteer team and the Community organizer.

The public AUTHORITY - the presence of the person directly responsible for solving the problem is very important. Representation will not be accepted.

It is the press that can ensure both the presence of the public Authority and the success of the Community initiative.

The aim of the assembly is to make the public Authority take the resolution of the problem using the proposed solution and to develop a concrete plan with deadlines for the authority to take on in public and to be published in the press.

Monitoring implementation (need resolution) - even if the role of the volunteer team is reduced after the public Assembly - it is still necessary to monitor the fulfillment of the plan by the Authority. If the Plan is not realized the Community action can continue along the lines proposed by the concept of "advocacy" with "civic disobedience" actions or other creative forms of pressure on the public Authority.

Selecting a new need - the process is a spiral process that resumes with selecting another need from the list and organizing to address this need. The Community organization process is rigorous and structured and, in compliance with the requirements of the proposed steps guarantee visible results at community level.

\subsection{Model Analysis}

The Community organization is one of the models involving almost all the factors specific to community development:

- initiated at local level - a local organization/structure decides to initiate the community organization process;

- involves an external specialist - the community organizer - who carries out a facilitation/organization process (as the main method used);

- is based on the action of an initiative group (rather the structure of leaders) - the volunteer group; involve community members in identifying problems and planning solutions; it generates social capital at community level - increases trust between members and involvement of members - a long-term process leads to the establishment of specific organizations

The weaknesses of the model are:

- the commission has already established that the project is not a project of common european policy, but a project of common european policy and of common european policy

- ownership of the results of your own actions, but can create a ownership of the process and actions that generated the results;

- it is difficult for all of them to apply the steps in small rural communities, where people know each other and where the press has little influence - local communication models are rather informal; in such communities some steps are short-circuited (are eliminated) and others are of much greater importance.

\subsubsection{The FRDS Model - The Model of the Local Initiative Group - GIL}

The model promoted by the Romanian Social Development Fund is also one of the models that formed the basis of the RuralNet model, most of those involved in its development, passing to the FRDR Community Development School. As a model, he is centered on the process by which an initiative group (group of informal leaders) is formed at local level, which will identify, prioritize and resolve a Community need.

The Community is also involved at the level of consultation on the decisions taken and, in particular, in the process of solving the Community problem/need where it has an active role in investing human and material resources.

The FRDS model consists of the following:

- the external facilitator who spends a number of the segments;

- facilitation of the Community-based sector - is the Community-led process of facilitator supporting the formation of the initiative group, the identification and prioritization of community needs, planning to 
address a need tailored to the specificities of projects funded by the FRDS, the implementation of the application for funding;

- the Community also takes the view that the aid is necessary in order to achieve the objective of common European Union law;

- the priority need identified in the facilitation process; once the application is complete, the role of the facilitator in the community is over;

- the Commission also considered that the measure was not selective;

- the results of the project are taken over by the local public Authority in the case of infrastructure projects or by the legal entity (firm) in the context of revenue-generating activities (AGV) projects.

\subsection{Model Analysis}

The FADS model is based on the 'high degree of standardization of industry practices' structured and provides substantial arguments for each methodological step it proposes.

The FADS model is one that follows the steps of a sustainable process in the community, following a simple and clear logic of the stages of community intervention

The project is based on the identification of informal leaders and development the links between them, on the one hand, and between them and the community, on the other, by creating the conditions for developing the community's social capital

The Commumity therefore concludes that the aid is necessary to ensure that the aid is limited to the costs of the project, and that the aid is limited to the costs of the project. And often lose sight of the essence of the Community development process - FRDS facilitators are assessed on the basis of the projects submitted by the facilitated communities and the assessment of the Community process almost lacks the explicit aspect of the FRDS itself - "the key function of facilitation has been, over time, the Increasing access for poor communities to FRDS projects"48.

The Community therefore takes the view that the public authorities have not been able to provide any information that would have been available to the public authorities segregation and division at community level, the idea is based on the principle of competition to get resources.

Although the model is one of the closest to the RuralNet standard by taking into consideartion that te limit to the stages of community planning and implementation of a community project, without considering the whole community development process (community capacity to strategically plan actions and implement plans) and even lose sight of the assessment of the impact on the community's share capital at the end of the project, the evaluation of the project being again focused on results.

The sore model has very good results in communities with crystallized initiative groups and was taken over by many organizations from Romania which later participated in the development of the RuralNet model: Rural assistance center, Romanian Association of Community Development, Pact Foundation.

\subsubsection{Local Community Organization}

As a model was applied in Romania by the Romanian Association of Community Development and developed later by the Partnership for Community Action and transformation Foundation. The model is process-oriented and requires capacity building through the organizational development of an initiative group.

The model was applied as a need for continued intervention in communities where the initiative groups have been set up in other interventions such as the CCGs (Advisory Committees for the implementation of Community actions) Developed under the RDP or local initiative groups developed under the FRDS program; where a project has been completed, a natural trend of the group has emerged.

The following steps are taken to develop the model:

- this is the case for the calculation of the noise level of the noise level;

- this is the case for the calculation of the noise impact of the noise impact;

- in the case of a public body, the commission will take into account the following information formal organizational;

- ommunity problem/need - project is to be implemented by the new structure organization created; 
- in the case of the project, the project will have to be designed to provide the necessary information for the project to be started.

\subsection{Model Analysis}

The model of the Community organization is centered on the development process community. The Community is at the heart of the model, the agent of change being an organized structure developed within the community.

The model acts on the Community's share capital, especially at the level of the Community social interaction networks by increasing the capacity of association at local level or by supporting its institutionalization where there is experience of association. Also, the sense of ownership of both the actions (process carried out) and the results of these actions is specific to this model of intervention.

As a Community development model, it specifically covers the first stages of the process and is centered on the community planning and community action stages and in some situations where the initiative group is already advanced on actions in the community, the very elements of strategic community development planning can be achieved.

It shall ensure the continuity and sustainability of the Community development process, as it also generates a local structure that will continue the process and which can generate, in turn, other structures of association at community level as a model

\subsubsection{The Community Network Model}

It is a model that is present at the level of most projects involving the more many communities or organizations from the same community or different communities - through the networking component.

A second dimension - going beyond the Community level of development is to increase the capacity of association, organization and mutual support of the structures community development initiated.

The role of this network structure is to support the community structures involved in the community development process by:

- the definition of the parameters for the calculation of the noise level is set out in the following sections;

- ; the commission therefore has to assess whether the aid is likely to have an impact.

The network approach also facilitates a shift from Community planning and action to strategic thinking, which is the first step toward strategic planning.

\subsection{Model Analysis}

Even if it is a model that does not specifically follow the stages of the development process Community - the Community network model is to support such a process, taking into account the following aspects:

- Yo contribute to increasing the interaction between members of the community and the associtiveness of the local level, by creating various community network structures where people are frequently gather for analysis of different local social situation;

- to participate in the strengthening of the community's organizational capacity by developing regional structure and networks,

- to generate social capital at regional and local level by increasing confidence members of the community in the capacity to organize and operate local community structures,

- to move from the community action stage to the strategic planning stage.

But as it has been applied so far in Romania, it is a model limited to this phase of community action and the first step of the regional approach to development, which requires a shift to strategic thinking and planning.

From the perspective of the local approach and the various formal structures initiated, even if it brings more interaction between members of the community, the legally imposed formalization often has negative effects that do not lead to longer-term behavior becoming more common.

2.6.1 Community Forum - For Planning Actions and Projects

The Community Forum model can have an internal or external initiator and this initiator can be an institution, an NGO or a local leader. It involves the following activities: 
- to set up a forum with members interested in a particular subject in the community (marginalized groups, cultural actions, attracting structural funds, etc.); in the forum identifies ideas that represent opportunities for developing and training working groups around each idea;

- the working groups are transforming the initial idea around which they were united into an action plan with responsibilities and deadlines;

- the community consultation process is also carried out in the form of forums for each individual action;

- the result of the implementation of the community forums is a project/or several projects that can be carried out in the community; and one or more initiative groups organized around a project idea.

\subsection{Model Analysis}

The model is centered on the planning phase of concrete actions. It short-circuits very much the first steps in the Community development process based on the involvement of local stakeholders who are aware of the local Community problem.

Another important aspect is that the model generates working groups that can be considered as local initiative groups.

The Community Forum transforms stakeholders into a network structure community made up of working groups and creating links between these actors, and generating share capital.

As a negative aspect of the implementation of this model (as implemented so far) we can emphasize the limited capacity to track applicability projects. The model responds well to the requirements of the start-up and planning stages of a Community project When it comes to resources - this project initiated is converted into a request for funding for which the evaluation period (until the project is funded) may last longer than the existence of the initiative group; or -- another possible situation -- is the one where the project is stuck in identifying the resources for its implementation.

If the Community Forum becomes a practical practice in the community - it brings an extra in the increase of the social capital of this community by generating trust and association.

\subsubsection{Micro-Region, Intercommunality, Regional Association}

This model has started as a form of organization for some communities with close specific in order to increase their organizational capacity and to approach development at a higher/wider Community level.

As an example of implementation in Romania, the first micro-regions appeared in the area of Transylvania - in Alba county and in the area of Marjornio (Harghita and Covasna counties) having been registered the first such forms of organization and development. The organization model of micro-regions was mainly the association of local councils/mayors that developed a micro-regional association. Specific legislation has subsequently emerged, defining inter-communality as a form of organization at micro-regional level, which has as its main responsibilities: Making water and canal infrastructure more efficient - collecting and filtering waste water and developing other infrastructure objectives specific to micro-regions.

The main elements of the model are:

- a Mayor or an NGO - which is the driving force for the initiation of the micro-regional approach to a development,

- the Community therefore takes the view that the public authorities are not in a position to control the operation of the public transport services for the named microoregion<

- a strategy (a plan) for the development of micro-region - containing the main directions and elements of development;

The main results of micro-regional development can be remembered:

- in the case of a public service contract, the public service contract is not covered by the public service contract, but by the public service contract, which is not covered by the public service contractl

- the main economic area of the main sector at the micro-regional level is strategic approach:

○ agriculture - setting up producer associations, pick-up and sales systems for agricultural products, etc.;

○ tourism - promotion of tourism at regional level. 


\subsection{Model Analysis}

As a Community development model - the development-oriented model micro-regional fulfills the following characteristics:

The process of the noise is a development initiator - a Mayor or an NGO - and often a he had a process facilitator. Association of Regional Community Development - SZEKE, Albamont or CHRONO - initiated and facilitated such development processes as well as in Micro-regional levels in Harghita, Alba and Dolj;

The Communuty therefore takes the following considerations into account:

- in order to implement concrete development projects; it comes to transfer development to micro-regional level where frequent local initiatives take place;

- the infrastructure is designed to be used to provide the necessary infrastructure for the transport of passengers and passengers, and to provide the necessary infrastructure for the transport of passengers and passengers.

- the Community also has to take into account the impact of the aid on the development of the infrastructure and the impact of the aid on the region implicitly and locally, and also increases trust capital to the level of APL structures and among communities in the region - as elements of share capital.

As a negative model, one can remember - the micro-regional approach dilutes the Community aspect of development and the Community's control of development.

\subsubsection{Leader Model - Local Action Group - Gal}

This model was initiated at European level as an alternative to the rigid implementation structure for the Structural Funds, which did not allow creative ideas to be applied at local level, especially in small rural communities.

The model has entered the structure of the European programs financed by the Structural Funds and in this way has been taken over by the Ministry of Agriculture and Rural Development (MADR) through the leader program, Axis IV of the NDRC.

It is a specific model of micro-regional development - specific to the conditions imposed by the national Rural Development Program - NDR - Axis IV leader.

Unlike the other axes of the NDRC, thematic axes - which specify which types of projects will be financed, the leader axis is a methodological axis - specify the process.

This process is provided by several conditions that must be met:

- the characteristics of the land-use area: a given area, a certain number of inhabitants, a maximum density in the territory;

- the fact that the public authorities are not involved in the development of the public transport system is not sufficient to establish the existence of a specific characteristic of the territory concerned. A specific form of relief - communities located on the Danube bank in the south of Mehedinti county, a predominant agricultural culture - region where the vine culture is specific, etc.);

A mixed associative structure (more than $50 \%$ private - business and NGO - and less than $50 \%$ public - mayors, public institutions) will be initiated, a structure that achieves a development strategy targeting that particular characteristic(s) of the territory.

The territory (NGO) is recognized as a local action group. This structure will have an operational office which will act as a financier which:

- the Community will assess the impact of the aid on the development of the area concerned;

- in the case of a public sector project, the public authorities will be involved in the development of the public sector.

The leader model offers:

- keep a good anchorage in the local area by transferring the component evaluation Strategic projects at local level - it is the GGA members who decide whether a the project is specific to or does not fall within the development strategy;

- the possibility of developing creative projects - the leader projects come to cover a Domain that other axes make difficult - to create something new and and creativity in developing this specific. 
Several organizations in Romania have initiated the implementation of type models Leader - ex: Leader Constanţa but as a government program he is the main requirement to comply with the program imposed by the MADR.

\subsection{Model Analysis}

The model is also one which dilutes the concept of a community with a micro-regional approach in which the specificity of the Community is integrated into regional specificities and the Community extends its limits to a region with several territorial communities (Leader territory is built as a micro-region even if it is focused on local elements).

As a model, leader is centered on the strategic planning and implementation stage of the strategy-specific projects developed at the level of the territory. This model, too, assumes the experience of Community development at local community level, which has led to the development of the more private partnership structure - as a development agent for the territory.

The model generates this local associative structure and the possibility of projects creative which are generating elements of social capital at local and micro-regional level.

Another positive aspect is the program for exchanging experience with other LAGs

In the EU, a program which is a generator of open relations and underpins the development of networks.

\subsubsection{Public-Private Partnership}

The public-private partnership model is a model that focuses on the development agent, which in this situation is a formal or informal structure generated by the association of a public institution with a private partner (firm or NGO).

Public-private partnerships are generally developed locally for specific issues:

- in the case of a project, the aid is not intended to be used;

- in the case of the public service compensation, the compensation for the discharge of public service obligations must be calculated on the basis of such partnership structures are generated.

The Community considers that the public funding of the public sector is an appropriate measure to address the specific objective of the public policy objectives of the public sector. The model may be a source of own revenue for the public Authority.

\subsection{Model Analysis}

The model is specific to the Community development process - to the operational planning and implementation stages of Community projects. It shall propose to the staff Member to do so initiate Community development - this agent being a structure (association or company) generated by associating public Administration with a private partner - depending on the specific project implemented.

The model is limited - because it does not follow the entire development process community but is limited to the implementation of specific development projects.

As a model, it generates association and local structures and if the projects implemented it is successful in generating social confidence - as a specific element of increasing the community's social capital.

\subsubsection{The Community Matrix}

The model was developed at Babes Bolyai University in Cluj and presented in the framework of the work for the Community matrix, knowledge, communication and common action in contemporary space (Mihai Pascaru, 2003).

The model requires a Community analysis of the following aspects:

- knowledge, communication and joint action at community level - reports generating the community matrix;

- participation at community level - participation that is reflected in the process of the fact

social and community dynamics;

- level of information and interpersonal communication at community level.

This model it actually focuses on a sociological analysis (survey) at the level

The Community on significant correlations between the three aspects of the community, the ability of investigators to obtain cooperation from their inhabitants and to accept the investigation from the outset and on their ability to return findings to the investigating authority. 
The return of the conclusions makes possible the involvement of the formal and informal leaders of the Community to "reinject" the results of research into the community in order to bring about the desired change at community level. A key feature of the model is the training of leaders in applying research findings.

The model also implies the existence of rural animators in team framework by sociologists, performers who:

- in the case of a public body, the public authorities must ensure that the public authorities are able to take appropriate measures to ensure that the public authorities are able to take the necessary measures to ensure that the public authorities are able to take appropriate measures to ensure that the public authorities are able to exercise their powers.

- in the case of a public authority, the public authority is responsible for the implementation of the public-public-public-public-law tasks

- proposed actions in relation to the characteristics of the community and the system of incentives for each groups;

- the commission therefore has to assess whether the public funding of the public service is necessary to achieve the public service tasks of the public service team frameworkby sociologists, performers who:in the case of a public body, the public authorities must ensure that the public authorities are able to take appropriate measures to ensure that the public authorities are able to take the necessary measures to ensure that the public authorities are able to take appropriate measures to ensure that the public authorities are able to exercise their powers.in the case of a public authority, the public authority is responsible for the implementation of the public-public-public-public-law tasksproposed actions in relation to the characteristics of the community and the system of incentives for eachgroups; the commission therefore has to assess whether the public funding of the public service is necessary to achieve the public service tasks .

\subsection{Model Analysis}

The Community matrix model is a complex model that takes into account almost all stages of the Community development process with a focus on certain aspects and stages in the process:

- this is a very important step in the analysis and knowledge of the community and the achievement of the project

- these stages with specialized sociologists to provide solutions to the community's problems.

Solutions being developed by specialists make it difficult to implement them in practice.

The level of joint action considers the transfer of experience to community leaders, who have a primary role in the implementation of the measures at community level.

Rge Community considers that the aid is compatible with the common market within the framework of the present case.

\subsubsection{Result Aspects of the Comunitary Development Models in the Countries Economy}

In Europe, the social economy has 2 million enterprises, which account for about $10 \%$ of total business and provide over 20 million jobs (10\%). For example, in France 760,000 organizations provide 2 million jobs, in Spain the social economy brings $10 \%$ of GDP and 51500 organizations provide 2.5 million jobs.

The data provided by the International Co-operative Alliance (ICA) show the share of cooperatives in the economies of the member countries of this organization.

Thus (International Co-operative Alliance):

$-30,000$ US cooperatives bring in over $\$ 500$ billion in revenue;

-In France the turnover of the cooperative system is 181 billion euros, and it holds $60 \%$ of the market - bank loans, $40 \%$ of food and agricultural production, $25 \%$ of retail trade;

-In Cyprus, cooperatives hold 35\% of the banking market and 35\% of the marketing market agricultural production;

-Cooperatives in Canada provide 35\% of the world's maple syrup production;

-In Denmark, consumer cooperatives accounted for $34.5 \%$ of the country's retail trade in 2007;

-The cooperative provides $74 \%$ of meat production, $96 \%$ of milk production, $50 \%$ of egg production, $34 \%$ of forestry production in Finland; 
-Hungary provided in 2004 14.4\% of the internal retail trade of foodstuffs, through cooperation and -In Poland, cooperatives provide $75 \%$ of milk production.

In terms of employment (ditto), the co-operative system provides more than 100 million jobs worldwide, $20 \%$ more than multinationals (for example: US 20 million jobs, Argentina 233 000, Canada 155,000, Czech Republic 56,042, France over 1 million, Slovakia 75,000, Spain-21.6\% of the labor market.

\section{Comments}

The theoretical models presented were selected from a variety of theoretical models of development at local level on the criterion of choosing the most significant features of the model, which are: adaptability to different situations, complexity, practical applicability.

The importance of these models is that, on the basis of them or on the basis of the aspect contained in their descriptions, other models can be developed, depending on the need for the situation.

The distinction from practical models, among which several elements will be presented as practical experiences, is that theoretical models are built from a concept or an idée, in time the practical models are built on the basis of previous theoretical models or practical experience adapted to the real needs of the situation.

\section{Conclusions}

The importance of local and regional economic-social development models is, first and foremost, to highlight the existence of an important instrument to underpin other local and regional economic and social development programs, based on the results of the operation of these models. The main result is the cohesion and organization, in society, of development strategies that involve and involve the members of society, in order to achieve trite economic standards, we have translated into social standards by raising the standard of living.

The models presented draw attention, in addition to their de facto existence, to the main social and economic co-oroates that can become aware of resources that can be used to develop new strategies and programs.

The choice of one or other of the presentation models, and the construction of new models, whether or not starting from those displayed, take account of the economic and social characteristics of the region of applicability and, at the same time, of the objectives pursued by the development of programs.

A very important aspect of appreciating the idea of the existence of social economic development for the application is that the use of such a model is urgently needed to achieve the objectives pursued in a more effective and efficient manner.

\section{References}

Brinkerhoff, D., \& Azfar, O. (2006). Decentralization and Community Empowerment.Does community empowerment deepen democracy and improve service delivery?. Washington, RTI International.

Credit Constraint Exports in Countries with Different Degrees of Contract Enforcement. Business and Economic Research, 7(1), 227-241.

Edwards, B., Foley, M., \& Diani, M. (2001). Beyond Tocqueville: Civil Society and the Social Capital Debate in Comparative Perspective. University Press of New England.

Friedmann, J. (1992). Empowerment. The Politics of Alternatives Development. Oxford, Wiley Blackwell.

Phillips, R., \& Pittman, R. (Eds.) (2008). An Introduction to Community Development. London: Routledge.

Ritzer, G. (1996). Sociological Theory (4th ed.). New York, McGraw-Hill.

Schumpeter, J. The Theorie of Economic Development. Harvard University Press.

Stanica, V. (2012). Dezvoltare comunitara. Bucharest Academy of Economic Studies.

Urban Development Division. (2001). The World Bank - Local Economic Development. Washington DC.

\section{Copyrights}

Copyright for this article is retained by the author(s), with first publication rights granted to the journal.

This is an open-access article distributed under the terms and conditions of the Creative Commons Attribution license (http://creativecommons.org/licenses/by/4.0/). 